\title{
Redescription of Microsporidium takedai (Awakura, 1974) as Kabatana takedai (Awakura, 1974) comb. n.
}

\author{
Jirí Lom ${ }^{1, *}$, Frank Nilsen ${ }^{2}$, Shigehiko Urawa ${ }^{3}$ \\ ${ }^{1}$ Institute of Parasitology, Academy of Sciences of the Czech Republic, Branišovská 31, 37005 České Budějovice, Czech Republic \\ ${ }^{2}$ Institute of Marine Research, PO Box 1870, Nordnes gt. 50, A - 5024 Bergen, Norway \\ ${ }^{3}$ Genetics Section, National Salmon Resources Center, Fisheries Agency of Japan, 2-2 Nakanoshima, Toyohira-ku, \\ Sapporo 062, Japan
}

\begin{abstract}
Ultrastructural study of the microsporidian Microsporidium takedai from the muscles of masu salmon Oncorhynchus masou proved that this species can be assigned to the genus Kabatana Lom, Dyková and Tonguthai, 2000. The parasites develop within disintegrated sarcoplasm without any delimiting boundary or cyst. Cylindrical multinucleate meronts proliferate by serial constrictions into uninucleate stages which repeat the process. Eventually, the uninucleate stages transform into uninucleate sporonts, which divide once to produce sporoblasts, thus functioning as sporoblast mother cells. Spores, with a subterminally located anchoring disc and 3 to 4 turns of the polar tube coil, average 3.3 by $1.9 \mu \mathrm{m}$ in size. The exospore is divided into small fields; the endospore frequently makes small invaginations into the spore inside. Phylogenetic analysis using SSU rDNA sequence consistently placed Kabatana takedai in a group consisting of Microgemma sp., Spraguea lophii and Glugea americanus. The $K$. takedai could easily be separated from the other species in the same group by 2 inserts in the SSU rDNA sequence.
\end{abstract}

KEY WORDS: Microsporidium takedai $\cdot$ Kabatana takedai $\cdot$ Microsporidia $\cdot$ Ultrastructure $\cdot$ SSU rRNA phylogeny · Oncorhynchus mykiss

\section{INTRODUCTION}

Microsporidium takedai is an important pathogen infecting the skeletal muscle and heart of wild and cultured salmonids in Hokkaido, Japan (Awakura 1974, Urawa 1989, Urawa \& Awakura 1994) and Sakhalin, Russia (Vyalova 1999). A number of taxonomic data have been collected on this species since its discovery as a Plistophora sp. by Takeda (1933). It was assigned to the same genus once again (Plistophora sp. of Awakura et al. 1966), then to the genus Glugea as G. takedai Awakura, 1974. Finally Miki \& Awakura (1977) suggested that based on their ultrastructural observa-

\footnotetext{
*E-mail: lom@paru.cas.cz
}

tions this species should be transferred to the genus Nosema, but they continued to call it Glugea. Canning \& Lom (1986, p. 163-165) considered none of these assignments to hold true and transferred it to the collective group Microsporidium as M. takedai.

We undertook the present ultrastructural and molecular study to reveal the exact taxonomic assignment of this species.

\section{MATERIAL AND METHODS}

Electron microscopy. The infected masu salmon Oncorhynchus masou were collected in the Chitose River on Hokkaido, Japan. Pieces of the infected trunk muscle were fixed for $4 \mathrm{~h}$ in $2 \%$ glutaraldehyde in

๑) Inter-Research 2001 
sodium cacodylate buffer, postfixed for $2 \mathrm{~h}$ in $2 \%$ osmium tetroxide, and embedded in Epon-Araldite. Ultrathin sections were double stained with uranyl acetate and lead citrate and examined in a Jeol JEM 1010 electron microscope at the accelerating voltage of $60 \mathrm{kV}$.

Molecular characterisation. Nucleic acid preparation: Infected tissue was stored in $70 \%$ ethanol until use. An aliquot of the spores was transferred to double-distilled water $\left(\mathrm{ddH}_{2} \mathrm{O}\right)$ and washed several times with repeated centrifugation in an Eppendorf Microfuge at $4000 \times g$ for $2 \mathrm{~min}$. The spores were then suspended in digestion buffer $(100 \mathrm{mM} \mathrm{NaCl}, 10 \mathrm{mM}$ Tris-HCl, 25 mM EDTA, 0.5\% sodium dodecyl sulfate, $\mathrm{pH} 8.0$ ) containing $0.5 \mathrm{mg} \mathrm{ml}^{-1}$ Proteinase $\mathrm{K}$ and incubated overnight at $37^{\circ} \mathrm{C}$. Nucleic acid was then extracted twice with an equal volume of chloroform/ phenol, followed by an equal volume of chloroform and then ethanol precipitated. The precipitated DNA was dissolved in $100 \mu \mathrm{lddH_{2 }} \mathrm{O}$.

Polymerase chain reaction (PCR): The PCR was carried out as described elsewhere (Nilsen 2000). Briefly, a set of primers (V1f and 1492r) was used to amplify the majority of the SSU rDNA gene. PCR was conducted in $100 \mu \mathrm{l}$ reactions using $20 \mathrm{pmol}$ of each primer, $20 \mathrm{nmol}$ of each dNTP, $10 \mu \mathrm{l} 10 \mathrm{X}$ Taq polymerase buffer (Advanced Biotechnologies, Surrey, UK), 2.5 units Taq polymerase, and $1 \mu \mathrm{l}$ of the above prepared genomic DNA. The reactions were run on a Perkin Elmer thermocycler for 35 cycles at $94^{\circ} \mathrm{C}$ for $1 \mathrm{~min}, 50^{\circ} \mathrm{C}$ for $1 \mathrm{~min}$, and $72^{\circ} \mathrm{C}$ for $2 \mathrm{~min}$. After completion of the 35 cycles, a 10 min extension at $72^{\circ} \mathrm{C}$ was applied. PCR products were visualised by running $10 \mu \mathrm{l}$ aliquots on a $1 \%$ agarose gel and then purified on a $1 \%$ low melting agarose gel. The band of desired size (approximately $1350 \mathrm{bp}$ ) was then excised from the gel.

Cloning and sequencing: The purified PCR product was sequenced in both directions using BigDye on an ABI prism 377. An aliquot of the purified PCR-product was cloned into TOPO TA cloning vector (Invitrogen, Carlsbad, CA) as described by the manufacturer. Plasmid from one clone containing an insert of correct size was partially sequenced using vector primers as described above.

Phylogenetic analysis: An alignment consisting of 37 microsporidia SSU RNA sequences was made as described in Nilsen (2000). Phylogenetic analyses were performed using PAUP* 4.0 version $4 \mathrm{~b} 4 \mathrm{a}$ (Swofford 1999). The data were analysed using parsimony, distance analysis and maximum likelihood. The parsimony analysis was performed using heuristic search with random addition of sequences and 100 subreplicates. For the distance analysis, the logdet distance measurement was used together with minimum evolution. In the maximum likelihood analysis a gamma correction was used to correct for rate heterogeneity across sites. The following species were used in the phylogenetic analysis: Amblyospora californica (U68473), A. simulii (AF027685), Amblyospora sp. (U68474), Ameson michaelis (L15741), Bacillidium sp. (AF104087), Culicosporella lunata (AF027683), Edhazardia aedis (AF027684), Encephalitozoon cuniculi (L39107), E. hellem (L39108), Endoreticulatus schubergi (L39109), Enterocytozoon bieneusi (L07123), Glugea anomala (AF104084), G. americanus (AF056014), G. atherinae (U15987), G. stephani (AF056015), Ichthyosporidium sp. (139110), Loma sp. (AF104081), Microgemma sp. (AJ252952), Microsporidium prosopium (AF151529), Nosema bombycis (D85504), Nucleospora salmonis (U78176), Pleistophora anguillarum (U47052), P. mirandellae (AF104085), P. typicalis (AF104080), Pleistophora sp. 2 (AF104083), Pleistophora sp. 3 (AF104082), Parathelohania anophelis (AF027682), Septata intestinalis (L39113), Spraguea lophii (AF104086), Thelohania solenopsae (AF134205), Trachipleistophora hominis (AJ002605), Vairimorpha necatrix (Y00266), Vavraia oncoperae (X74112), Visvesvaria algerae (AF024656), V. acridophagus (AF024658), Vittaforma corneae (L39112).

\section{RESULTS}

\section{Light microscopy}

Spores are ovoid or elongated oval with one end wider or slightly comma-like curved (Fig. 1). The large posterior vacuole occupies more than the posterior third; its anterior boundary appears either oblique or perpendicular to the spore length. The size of spores $(\mathrm{n}=20)$ from our sample was $3.3(4.5-6.2) \times 1.9$ (1.6 - 2.1) $\mu \mathrm{m}$ (measured from photographic prints). Polar tube could not be discerned in live spores.

Figs. 1 to 7. Kabatana takedai. Fig. 1 . Live spores of $K$. takedai. Scale bar $=5 \mu \mathrm{m}$. Fig. 2. Cylindrical meronts in a longitudinal section embedded in the disintegrated sarcoplasm (S). n: nuclei. Scale bar $=2 \mu \mathrm{m}$. Fig. 3. Meronts in transverse section. Scale bar $=2 \mu \mathrm{m}$. Fig. 4 . At the top, meront undergoing constrictions in the process of division into single cells; at the bottom, a chain of new cells which will differentiate into sporonts. n: nuclei. Scale bar $=2 \mu \mathrm{m}$. Fig. 5 . A meront with 1 nucleus in which parts of the nuclear envelope (arrows) have been transformed into stacks of myeline-like membranes. Scale bar $=2 \mu \mathrm{m}$. Fig. 6 . The stack of myeline-like membranes from Fig. 5. Scale bar $=200 \mathrm{~nm}$. Fig. 7. Disintegrated sarcoplasm (S) between 3 meronts (m). Arrows point to the globules close to the meront cell membranes. Scale bar $=0.5 \mu \mathrm{m}$ 


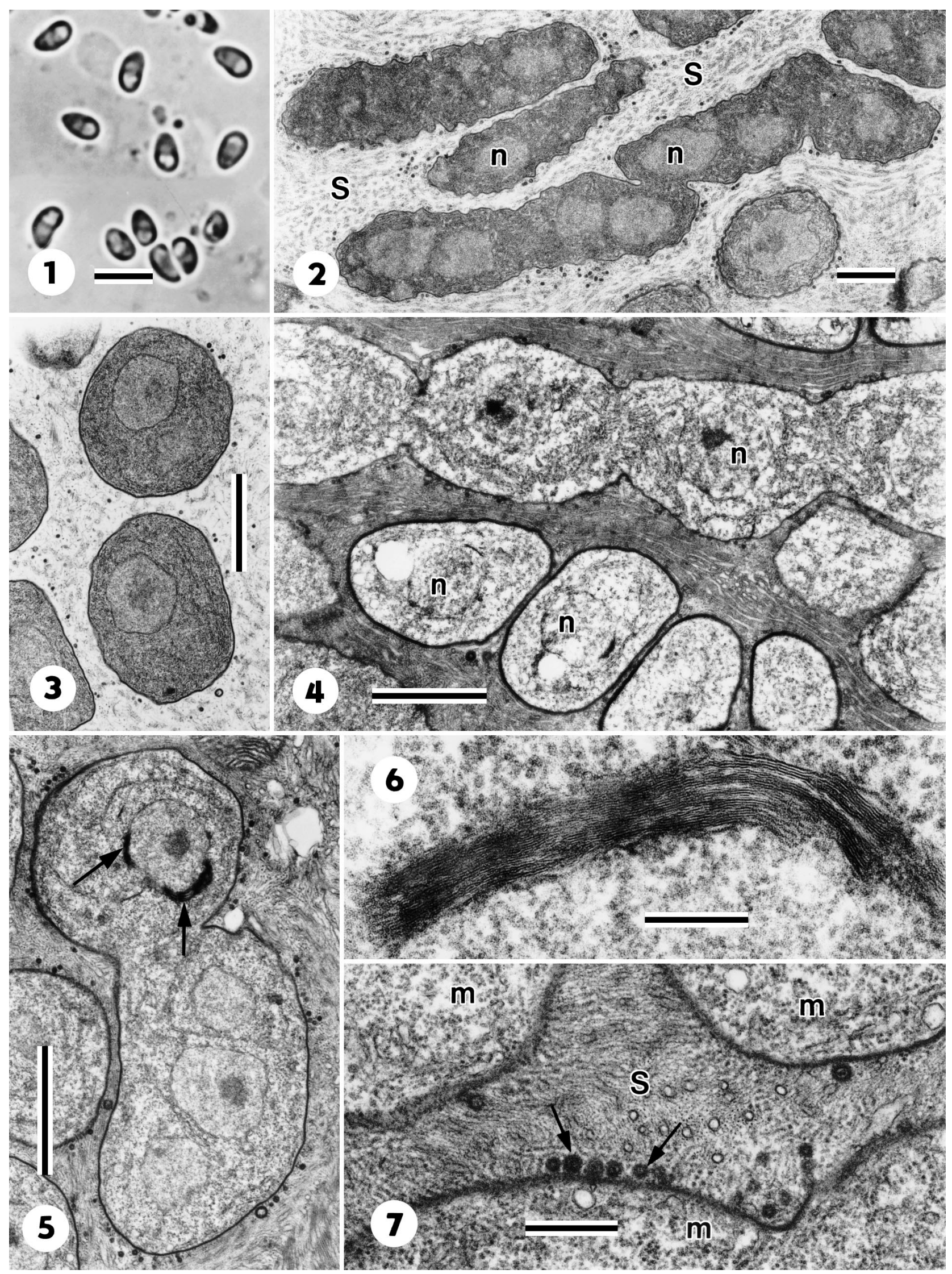




\section{Electron microscopy}

In the infected trunk musculature the parasites form foci, sometimes very large, in which the developmental stages and spores are situated within a completely degraded sarcoplasm. The prevailing structures are indeterminate fibrils, membranous vesicles, cisternae and canaliculi located sometimes in finely granular substance. The parasite focus is in no way delimited by any boundary of intact muscle cells. There is a certain stratification of the parasites; meronts tend to be situated at the periphery of the focus, their long axis perpendicular to the long axis of the focus periphery.

\section{Merogony}

Meronts grow from uninucleate stages to long multinucleate cylinders reminiscent of those of Glugea, with serially arranged nuclei (Figs. 2 \& 3). The cytoplasm contains free ribosomes, some vesicles and isolated cisternae of endoplasmic reticulum. Sometimes the long cylinder is branched as if budding off a new one. Eventually, the cylinders are constricted serially to produce a row of new cells, either new meronts or sporogony cells (Fig. 4). The centriolar plaques are represented by thickenings of the 2 membranes of the nuclear envelope facing a few inconspicuous globular membranous structures. The plasmalemma is covered by a thin layer of cell coat. Two features have to be mentioned. The nuclear envelope of some meronts of normal appearance is in some parts of its circumference transformed into a stack of up to 20 fine, myelin-like membranes (Figs. $5 \& 6$ ). Further, the cell wall of meronts - as well as that of early sporonts-may be flanked by series of vesicles which appear as if the vesicle wall has been pinched off from the meront wall. The fine fibres and tubules left in the degraded sarcoplasm around the cells seem to be attached to the meront wall (Fig. 7).

\section{Sporogony}

Cells, produced, as a rule, by serial cleavage of a merogonial cylinder are characterised by a thicker (ca $55 \mathrm{~nm}$ ) cell coat (Fig. 8); the plasmalemma is covered by an amorphous dense layer on the top of which is what resembles a unit membrane (Fig. 9). These cells, actually sporonts, have a well-developed cisternae of rough endoplasmic reticulum and nuclei with eccentric nucleoli. The sporonts undergo 1 more cell division (Figs. $10 \& 11$ ) so that they are in fact sporoblast mother cells. From this stage on, the future exospore differentiates when the surface membrane begins to make invaginations into the amorphous layer. On the outer face of this membrane strand-like initiations of the future outermost exospore layer can be found, appearing in transverse sections as tiny (about $17 \mathrm{~nm}$ across) knobs of dense substance. These knobs can be seen on maturing spores, giving it a slightly frayed appearance (Fig. 12). Early sporoblasts are surrounded by a few tubules about $80 \mathrm{~nm}$ in diameter, evidently produced by the cells undergoing sporogony (Fig. 12). In very early sporoblasts the primordium of the polar tube appears (Fig. 13) as well as a dense globule which persists up to the stage of an almost mature spore (Fig. 14).

In the maturing spore when the developing anchoring disc is still pillow-like (Fig. 14), the gradually growing polar tube is at first moderately tapering to the end, eventually the turns of the coil assume the same diameter, i.e., the tube is isofilar. In a mature spore, the anchoring disc is subterminal (Fig. 15) and the straight part of the tube extends obliquely backwards to the spore wall for a coil of 3 to 4 turns in 1 rank. The anterior part of the polaroplast (see Fig. 21) consists of a conical stack of closely adhering lamellae which are spaced at an interval of about 50 to $100 \mathrm{~nm}$, according to the effect of fixation, and are situated obliquely to almost perpendicularly to the straight shaft of the polar tube. The posterior part is formed by flat alveoli containing dense substance and is situated slightly ob-

Figs. 8 to 19. Kabatana takedai. Fig. 8. Sporonts produced by constriction of a meront cylinder. n: nuclei. Scale bar $=1 \mu$ m. Fig. 9. Cell walls of sporonts from Fig. 8; single arrow points to the cell membrane, double arrows point to the membrane cover-

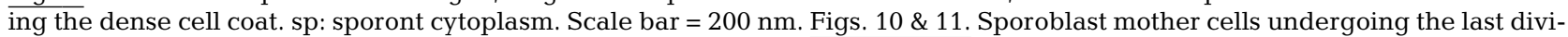
sion into sporoblasts. n: nuclei. Scale bars $=1 \mu \mathrm{m}$. Fig. 12. Exospore of an almost mature spore with a lamina (thin arrow) forming invaginations to delimit discrete exospore fields and covered by strands of dense substance (open arrow). Scale bar $=0.5 \mu \mathrm{m}$. Fig. 13. Early sporoblast with primordium of the polar tube (arrow). Scale bar $=0.5 \mu \mathrm{m}$. Fig. 14. Immature spore with a pillow-like polar sac (arrow), nucleus (n) and dense globular inclusion $(\mathrm{g})$. Scale bar $=2 \mu \mathrm{m}$. Fig. 15. Mature spore with subterminal position of the anchoring disc and obliquely extending polar tube. n: nucleus. Scale bar $=0.5 \mu \mathrm{m}$. Fig. 16 . A spore with laminar $(*)$ and alveolar (arrow) parts of the polaroplast and strands of polyribosomes in the posterior part of the spore. Scale bar $=0.5 \mu \mathrm{m}$. Fig. 17. Bulge of the endospore. Scale bar $=0.5 \mu \mathrm{m}$. Fig. 18. Two bulges of the endospore, one with a dense substance inside.

Scale bar $=0.5 \mu \mathrm{m}$. Fig. 19. Exospore (e) with dense substance (open arrow) covering the outer lamina. Scale bar $=200 \mathrm{~nm}$ 


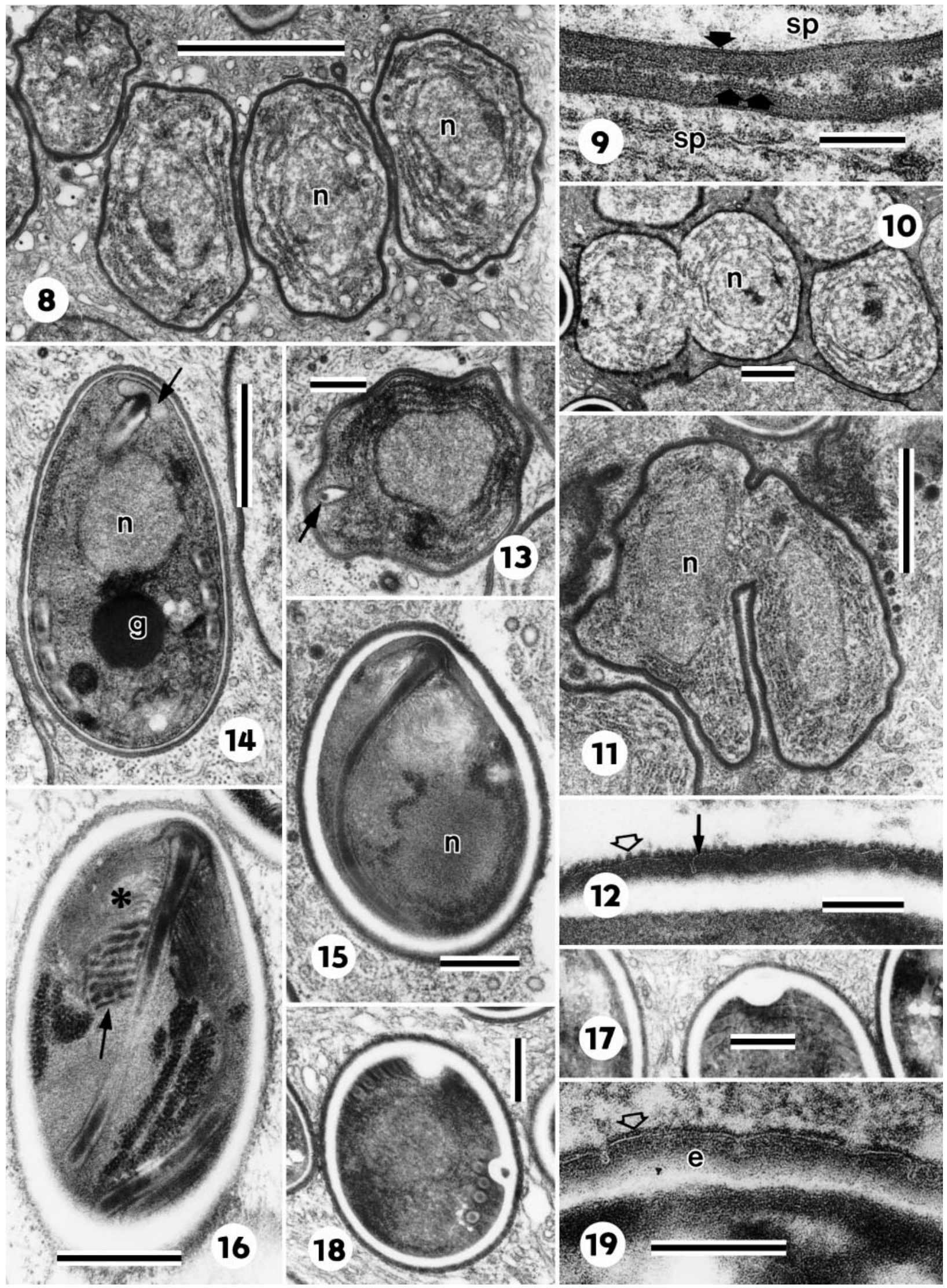


liquely to the straight part of the tube (Fig. 16). The round nucleus with regularly dispersed aggregates of chromatin and without a nucleolus occupies a central position in the spore. The sporoplasm contains conspicuous masses or strands of polyribosomes. The dense globule disappears completely in mature spores.

The endospore and the exospore average 100 and $70 \mathrm{~nm}$ in thickness, respectively. In many spores the endospore is deeply invaginated into sporoplasm at 1 (Fig. 17) or 2 places (see Fig. 20); sometimes this invagination includes a dense centre as if it were a piece of cytoplasm (Fig. 18). It was not possible to determine what happened to plasma membrane when the endospore invaginated. At the surface of the dense substance of the exospore there is a unit membrane-like lamina, itself covered by a thin layer of dense substance, which originated from the strand-like initiations at the surface of sporoblasts. This lamina makes incisions into the dense exospore substance (Fig. 19), thus delimiting small fields on the surface of the spore.

There are always some abnormal spores to be seen, some differing only by having 2 nuclei, as if the division of the sporoblast mother cell had not been accomplished.

\section{Molecular analysis}

The amplified PCR product from Kabatana takedai was $1375 \mathrm{bp}$ with a GC content of $46.5 \%$ and the sequence has been submitted to GenBank with accession number AF356222. Using parsimony, distance analysis and maximum likelihood analysis, we obtained trees with very similar overall topology. The phylogenetic analysis consistently placed $K$. takedai in a group consisting of Microgemma sp., Spraguea lophii and Glugea americanus. The bootstrap support for this group was highly independent of methods used (97 to $99 \%$ support) (see Fig. 22). In all the analyses $K$. takedai was placed as a sister species to the remaining species in this group (Fig. 22). Furthermore, $S$. lophii and $G$. americanus were grouped together with Microgemma sp. as a sister species. All these groupings were supported by high bootstrap values (Fig. 22). This group is a sister group to a group in which all the remaining fish-infecting microsporidia occur, bar Nucleospora salmonis, which lies in a clade with Enterocytozoon bieneusi. The K. takedai could easily be distinguished from the other microsporidian species occurring in the same group by 2 inserts in the SSU rDNA sequence. A $12 \mathrm{bp}$ insert from position 191 and a $19 \mathrm{bp}$ insert from position 1019 were unique to the $K$. takedai sequence (numbers refer to the $K$. takedai sequence).

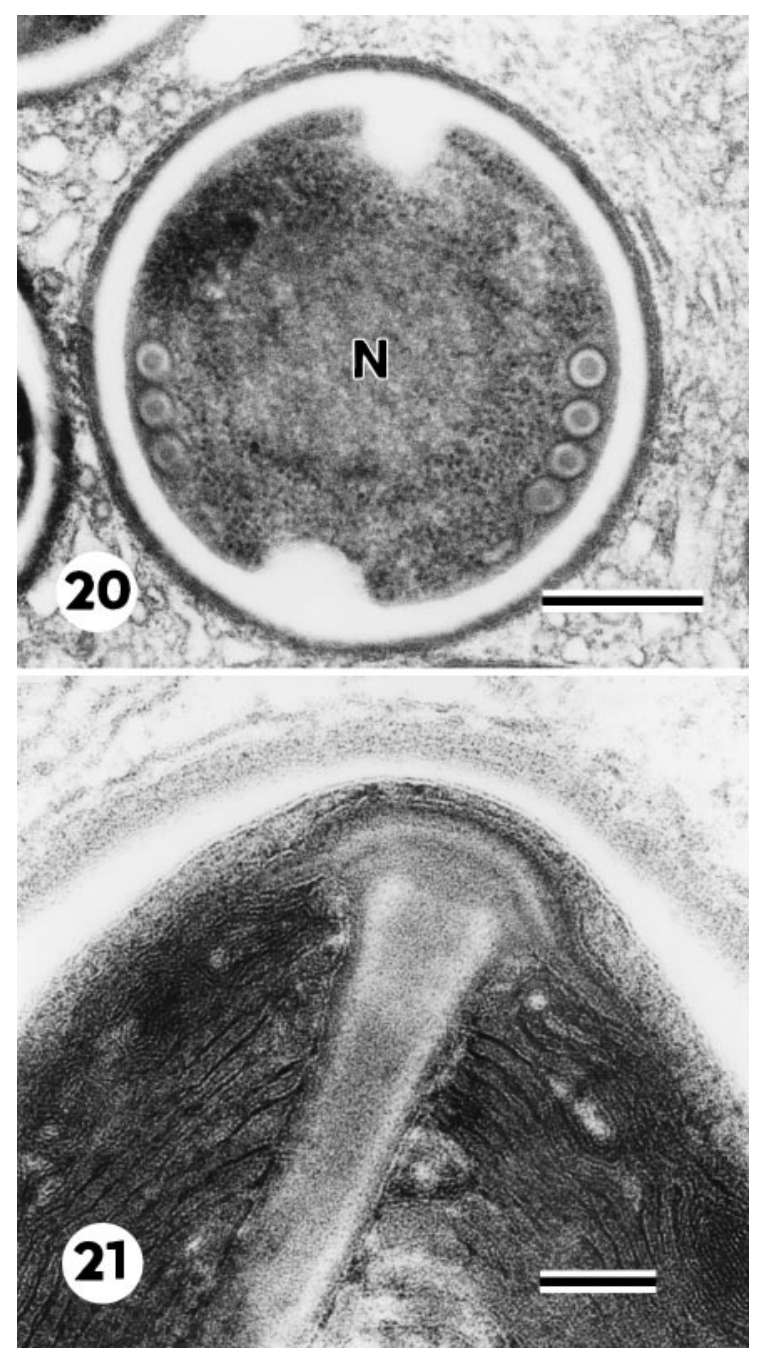

Figs. 20 \& 21. Kabatana takedai. Fig. 20. Two invaginations of the endospore at opposite sides of the spore. N: nucleus. Scale bar $=200 \mathrm{~nm}$. Fig. 21. Anchoring disc of the spore and the lamellar part of the polaroplast. Scale bar $=100 \mathrm{~nm}$

\section{DISCUSSION}

Miki \& Awakura (1977), in their ultrastructural study of the microsporidian that they continued to call Glugea takedai, came to the conclusion that the spores originated from the sporont directly without any division. This is at variance with Awakura (1974), who in his Fig. 10 clearly depicted division of the sporont, i.e., of the sporoblast mother cell, into 2 sporoblasts. It also differs from our observations in this study. However, other interpretations of Miki \& Awakura (1977) may not have been quite exact since, in their schematic drawing of G. takedai (their Fig. 2), they depicted a structure which they called a nucleus embracing a separate structure, which they designated as the sporo- 


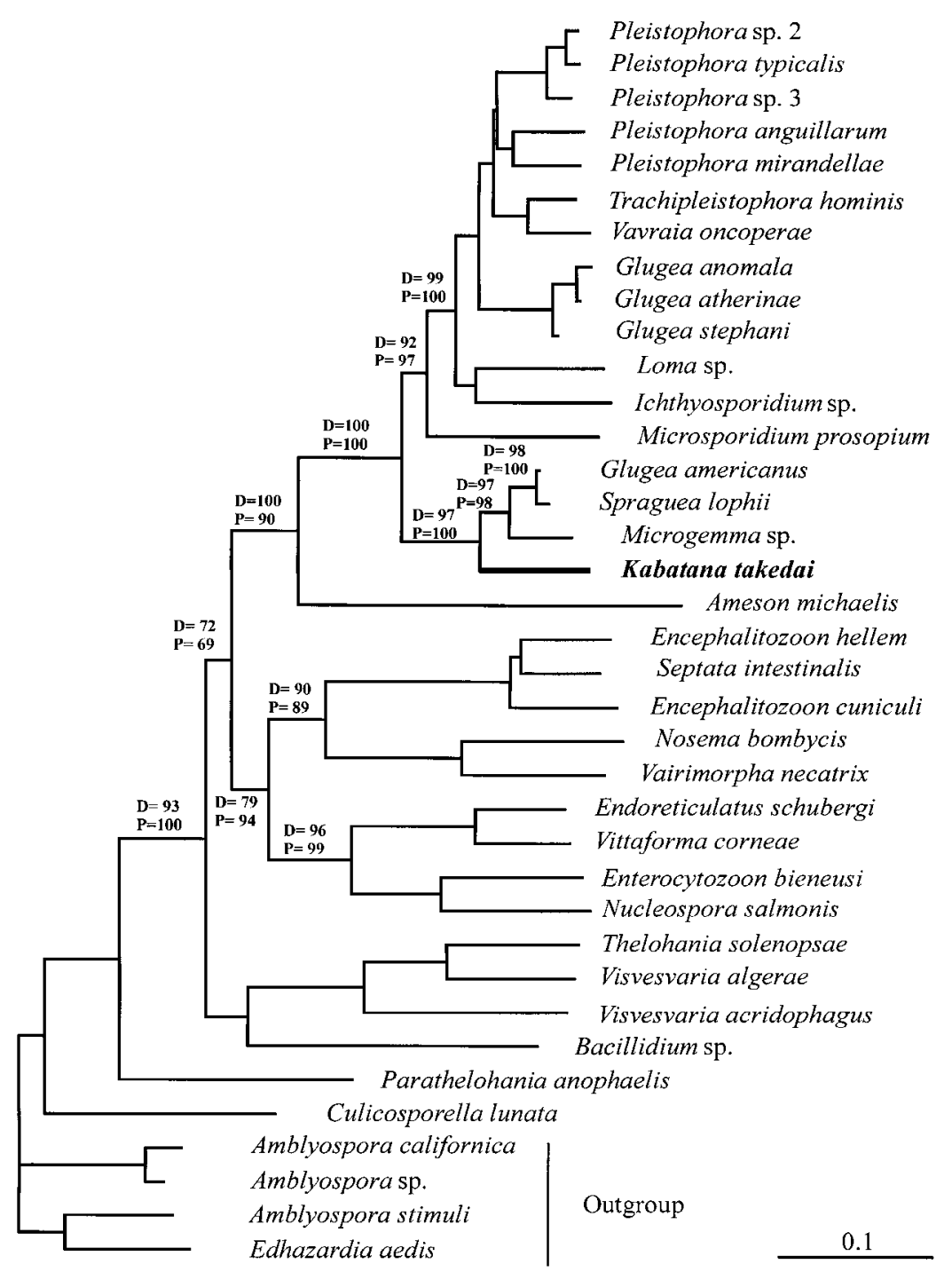

Fig. 22. Maximum likelihood tree showing the phylogenetic position of Kabatana takedai. The numbers on the branches represent bootstrap support using parsimony (P) and puzzle using distance (D) as optimum criterion. 1000 replicates were used with both methods. Only bootstrap values relevant for the present study are shown to get a tree that is easy to read. Pleistophora sp. 2 and Pleistophora sp. 3 correspond to the same species as in Nilsen et al. (1998). Branch lengths are calculated using puzzle in PAUP* 4.0. Amblyospora californica, Amblyospora sp., Edhazardia aedis and A. simulii are used as outgroup. GenBank accessions Glugea americanus and Pleistophora anguillarum are listed with the species names when they were entered in the GenBank
Lom et al. (2000) since it was found that Kabataia was preoccupied by Kabataia ostorhinchi, a parasitic copepod). The foci of infection in disintegrated myocytes of the trunk musculature are the same; spores are of almost identical size, and only the outlines of the posterior vacuole differ, as they are not as globular as in $K$. arthuri. Meronts are more regularly cylindrical in $M$. takedai and produce daughter cells by serial cleavage while in $M$. arthuri they are produced also by segmentation of rounded or irregularly shaped meronts. In sporogony there is a difference: in $K$. arthuri, a multinucleate meront transforms while segmenting into uninucleate cells, which are actually the sporoblast mother and give rise to 2 sporoblasts. In $M$. takedai, however, it is only in the uninucleate products of the serial cleavage of the cylindrical meronts that the sporogonial transformation sets in, these cells then becoming the sporoblast mother cells.

The anatomy of the spores is very similar, too, except for the slightly different number of turns of the polar tube -3 to 4 in Microsporidium takedai and 4 to 7 (mean 5) in Kabatana arthuri. The polaroplast reaches slightly more posteriorly in spores of $M$. takedai.

Microsporidium takedai doubtlessly belongs to the genus Kabatana. In spite of the rather minor differences from $K$. arthuri, we prefer not to consider it conspecific because of different hosts from different families assigned to different orders and different areas of distribution, unless future molecular techniques indicate conspecificity. Closely related species are $K$. seriolae from yellowtail Seriola quinqueradiata (Egusa, 1982) and most probably Microsporidium sp. from red sea bream Pagrus major (Egusa et al. 1988).

Stacks of myeline-like membranes forming part of the nuclear envelope of meront nuclei are probably an anomalous phenomenon in the development of the microsporidian. The same probably applies to the invaginations of the endospore, a feature unique in microsporidia which cannot be taken as a feature characterising this species. No information has been obtained concerning the nature of the electron-dense globules which occur in the sporoblasts and imma- 
ture spores of Kabatana. The same inclusions were recorded in immature spores of other fish-infecting microsporidia, e.g., Glugea anomala (Schmahl \& Mehlhorn 1989), Ichthyosporidium giganteum (Sprague \& Vernick 1974), Loma acerinae (Lom \& Pekkarinen 1999) or Nosemoides syacii (Faye et al. 1994), and it certainly occurs in microsporidia from other hosts.

The phylogenetic analysis shows with high confidence that Kabatana takedai is most closely related to Spraguea lophii and Microgemma sp. as all our analyses grouped these species together (see Fig. 22). All 3 species could be clearly separated due to the presence of unique sequence motifs in the SSU rDNA (i.e., signature sequences). These 3 species are within group III as defined by Nilsen (2000), a group almost exclusively comprising fish-infecting microsporidia (see Fig. 22). Several of the microsporidia included in the present phylogenetic analysis infect the muscle of fish (i.e., Pleistophora typicalis, Pleistophora sp. 2. Pleistophora sp. 3, Microsporidium prosopium and K. takedai). K. takedai infects the trunk muscle but it is not related to any other of the muscle-infecting microsporidia included in the present study. Nilsen et al. (1998) showed that other muscle-infecting microsporidia from fish did not form a monophyletic group. K. takedai is another example of a microsporidium infecting muscle in fish that is not related to Pleistophora spp. This is also the case with $M$. prosopium from the muscle of Prosopium williamsoni (Kent et al. 1999).

Nilsen (2000) discussed the relation between the microsporidia infecting the European and American anglerfish (i.e., Lophius piscatorius and L. americanus). The phylogenetic analysis using SSU rDNA sequence showed that these 2 microsporidia are closely related. The Glugea americanus sequence was obtained from $L$. americanus and the present analysis confirms the view of Nilsen (2000) that the microsporidia in L. americanus belongs to Spraguea and not to Glugea as suggested by Takvorian \& Cali (1986). There are some striking differences between the species occurring in the same group as Kabatana takedai. Spraguea lophii has a dimorphic development and produces both mononucleated and diplokaryotic spores in 2 different developmental cycles. The 2 other species, K. takedai and Microgemma sp., have isolated nuclei throughout the developmental cycle. Furthermore, all genera in this group infect different cell types, i.e., nerve cells in the central nerve system for $S$. lophii and G. americanus, trunk muscle for $K$. takedai and hepatocytes for Microgemma sp.

Acknowledgements. This paper was supported by the Grant Agency of the Czech Republic, Grant No. 524/98/0589 and by the Grant Agency of the Academy of Sciences of the Czech Republic, Grant K2-022-601.

\section{LITERATURE CITED}

Awakura T (1974) Studies on the microsporidian infection in salmonid fishes. Sci Rep Hokkaido Fish Hatchery 29:1-95 (in Japanese)

Awakura T, Kurahashi S, Matsumoto H (1966) Studies on the Plistophora disease of salmonid fish-II. Occurrence of the microsporidian disease in a new district. Sci Rep Hokkaido Fish Hatchery 21:1-11 (in Japanese)

Canning EU, Lom J (with the cooperation of Dyková I) (1986) The microsporidia of vertebrates. Academic Press, London

Egusa S (1982) A microsporidian species from yellowtail juveniles, Seriola quinqueradiata, with 'beko' disease. Fish Pathol 16:187-192 (in Japanese)

Egusa S, Hatai K, Fujimaki Y (1988) Notes on Microsporidium species, the etiological agent of 'beko' disease in red sea bream juveniles, Pagrus major. Fish Pathol 23:263-267 (in Japanese)

Faye N, Toguebaye BS, Bouix G (1994) Nosemoides syacii n. sp., a microsporidian parasite of the West African turbot Syacium micrurum Ranzani, 1840. Syst Parasitol 29:43-50

Kent ML, Docker J, Khattra J, Vossbrinck CR, Speare DJ, Devlin RH (1999) A new Microsporidium sp. (Microsporidia) from the musculature of the mountain whitefish Prosopium williamsoni from British Columbia: morphology and phylogeny. J Parasitol 85:1114-1119

Lom J, Pekkarinen M (1999) Ultrastructural observations on Loma acerinae (Jírovec, 1930) comb. nov. (Phylum Microsporidia). Acta Protozool 38:61-74

Lom J, Dyková I, Tonguthai K (1999) Kabataia gen. n., a new genus proposed for Microsporidium spp. infecting trunk muscles of fishes. Dis Aquat Org 38:39-46

Lom J, Dyková I, Tonguthai K (2000) Kabatana gen. n., new name for the microsporidian genus Kabataia Lom, Dyková et Tonguthai, 1999. Folia Parasitol 47:78

Miki S, Awakura T (1977) The fine structure of Glugea takedai Awakura, 1974 (Microsporida, Nosematidae). Sci Rep Hokkaido Fish Hatchery 32:1-19 (in Japanese)

Nilsen F (2000) Small subunit ribosomal DNA phylogeny of Microsporidia with particular reference to genera that infect fish. J Parasitol 86:128-133

Nilsen F, Endresen C, Hordvik I (1998) Molecular phylogeny of microsporidians with particular reference to species that infect the muscle of fish. J Eukaryot Microbiol 45:535-543

Schmahl G, Mehlhorn H (1989) Treatment of fish parasites. 6. Effects of sym-triazinone (Toltrazuril) on developmental stages of Glugea anomala Moniez, 1887 (Microsporidia): a light and electron microscopic study. Eur J Protistol 24:252-259

Sprague V, Vernick S (1974) Fine structure of the cysts and some sporulation stages of Ichthyosporidium (Microsporida). J Protozool 21:667-677

Swofford DL (1999) PAUP*. Phylogenetic analysis using parsimony (*and other methods). Version 4. Sinauer Associates, Sunderland, MA

Takeda S (1933) On a new disease of rainbow trout. Keisoniho 5:1-9 (in Japanese)

Takvorian PM, Cali A (1986) The ultrastructure of spores (Protozoa: Microsporidia) from Lophius americanus, the angler fish. J Protozool 33:570-575

Urawa S (1989) Seasonal occurrence of Microsporidium takedai (Microsporida) infection in masu salmon, Oncorhynchus masou, from the Chitose River. Physiol Ecol Jpn (Spec) 1:547-598

Urawa S, Awakura T (1994) Protozoan diseases of freshwater fishes in Hokkaido. Sci Rep Hokkaido Fish Hatchery 48: 47-58

Vyalova GP (1999) Diseases of Sakhalin salmon (review). Sci Rep Hokkaido Fish Exp Stn 54:47-51

Submitted: September 26, 2000; Accepted: December 5, 2000 Proofs received from author(s): April 9, 2001 